\title{
Pallister-Killian Syndrome
}

National Cancer Institute

\section{Source}

National Cancer Institute. Pallister-Killian Syndrome. NCI Thesaurus. Code C75458.

A very rare chromosomal disorder caused by tetrasomy of chromosome $12 \mathrm{p}$. It is characterized by severe mental retardation, prominent forehead, sparse temporofrontal hair, hypertelorism, short nose, and streaks of hypopigmented skin. 